University of Nebraska - Lincoln

DigitalCommons@University of Nebraska - Lincoln

2004

Sociality and the Evolution of Intelligence

Alan Kamil
University of Nebraska - Lincoln, akamil1@unl.edu

Follow this and additional works at: https://digitalcommons.unl.edu/bioscibehavior

Part of the Behavior and Ethology Commons

Kamil, Alan, "Sociality and the Evolution of Intelligence" (2004). Papers in Behavior and Biological Sciences. 43.

https://digitalcommons.unl.edu/bioscibehavior/43

This Article is brought to you for free and open access by the Papers in the Biological Sciences at DigitalCommons@University of Nebraska - Lincoln. It has been accepted for inclusion in Papers in Behavior and Biological Sciences by an authorized administrator of DigitalCommons@University of Nebraska - Lincoln. 


\title{
Sociality and the Evolution of Intelligence
}

\author{
Alan C. Kamil
}

School of Biological Sciences and Department of Psychology, University of Nebraska-Lincoln, Lincoln, NE 68588-0 I I8, USA

\begin{abstract}
Two recently published studies provide important new data relevant to the evolution of human intelligence. Both studies of social behavior in baboons, Bergman et al. demonstrated that baboons use two criteria simultaneously to classify other troop members, and Silk et al. showed that highly social female baboons have higher reproductive success than less social females. Taken together, these studies provide strong evidence for the importance of social context in cognitive evolution.
\end{abstract}

Human intelligence appears to be unique in the biological world, but how did it arise? Its very existence raises two fascinating and difficult questions. What evolutionary factors have given rise to human intelligence? How great is the discontinuity between the mental life of humans and that of other animals? Two recent field studies of baboons provide powerful evidence bearing on these issues. Bergman, Seyfarth et al. have shown that baboons in the wild can classify other members of their troop by two criteria simultaneously - kinship and individual dominance rankimplying that baboons use a rule-governed hierarchical classification system when making judgments about dominance status [1]. Furthermore, Silk et al. showed that the sociality of female baboons is positively correlated with survival of their offspring, demonstrating a potent selective advantage to females who are more successful in establishing and maintaining social relationships [2]. If the social knowledge implied by the classification of troop members can be demonstrated to contribute to the reproductive success of highly social baboons, this would provide a compelling case for the hypothesis that social context provides powerful selective advantages for cognitive evolution.

\section{Judging dominance relationships}

The study of classification of dominance status [1] was made possible by considerable knowledge of the social world of baboons and other Old World monkeys from previous research [3, 4, 5 and 6]. This earlier work showed that monkeys recognize dominance status and kin relationships among members of their troop and that the social structure of the females in a baboon troop is organized according to matriline. Within each set of adult females and their mature daughters, dominance is linearly arranged with the mother as dominant, and each daughter dominant to all older daughters in that matriline (daughters take on the rank just below that of their mothers on reaching maturity).
At another level, the matrilines are themselves arranged in a linear hierarchy: for any given pair of matrilines, all members of one matriline will be dominant to all members of the other. This raises the question of whether the monkeys' representation of the dominance structure of the females in a troop encodes for different types of dominance within and between families.

To answer this question, Bergman et al. conducted a playback experiment [1]. Over the course of several field seasons, a library of calls of troop members was assembled. The researchers created tapes from this library, which presented a sequence of calls that mimicked a fight between two females. Each of these tapes presented dominant threat-grunts by one female and subordinate fear screams of another. In some cases, the incident portrayed was a dominance reversal, with the subordinate screams coming from an animal who was actually dominant to the animal giving the grunt. In one treatment, the two individuals were from the same family; in other cases, they were from different families. There were also control tapes in which the interaction portrayed was not a reversal. The results of the playback experiment clearly demonstrated that the baboons reacted more strongly to between-family reversals than to within-family reversals.

What do these results tell us about the social knowledge of these monkeys? There can be no doubt that the baboons treat within- and between-family reversals of dominance differently. This is consistent with a hierarchical representation of dominance relationships. As the authors conclude: 'These experiments provide evidence that monkeys classify others simultaneously according to both their individual attributes and their membership in higher order groups, and that they do so in the absence of human training' (p. 1236). They further suggest this might represent a cognitive ability important to human language, as it demonstrates the use of the kind of rule-governed hierarchies that are important in language, particularly the understanding of sentences [7].

\section{The selective advantages of sociality}

But is there any point to this knowledge? Most cognitive scientists think it obvious that it is better to be smart than stupid, informed than not informed. This is not obvious, however, to the evolutionary biologist. There is a very high cost to maintaining the brain tissue that makes cognition possible [8]. The benefits, therefore, must be substan- 
tial. The empirical challenge for the evolution of cognition is twofold: to figure out the contexts in which knowledge is important and the ways in which knowledge confers selective advantage. Although the results of Bergman et al.'s research [1] inform us about the social knowledge of baboons, they do not reveal the selective advantage of such knowledge, if any. Many have assumed that increased sociality and cognition are advantageous, but there has been little direct evidence. The first hard evidence on this issue is now published in the paper by Silk et al. [2].

This research was made possible by extensive previous field research. About 34000 samples of behavior from 108 female baboons were analyzed. The samples were drawn from two long-term field studies of baboons - a total of 16 years of observation. Silk et al. measured three aspects of the degree of sociality of the females: spatial proximity to other adults, being groomed by others, and grooming others. They found that a composite index of sociality based on these measures was highly correlated with infant survival. Females who were more social had more infants that survived the first year of life, the most dangerous time for these infant monkeys. Clearly, highly social females had higher reproductive success than less social females. Remarkably, this correlation was independent of the effects of dominance rank, environmental conditions or group membership. These results provide the first direct evidence of the selective advantage of sociality in primates.

\section{The evolution of intelligence}

Taken together, these studies provide strong evidence that the social milieu has provided an important context for cognitive evolution. Baboons appear to possess complex, hierarchically organized information about social status and relationships [1] and sociality itself has major consequences for fitness [2]. If the ability to make sophisticated judgments about relationships between conspecifics contributes to social success, as seems to be the case from these results, then we have clear evidence linking social cognition to biological success. As field biologists continue to study the knowledge possessed and used by animals and how possession of this knowledge can confer selective advantage, it will become apparent that under some circumstances, selection has favored complex cognitive abilities [9].

These results are also important for the developing field of human evolutionary psychology, the attempt to understand our species in an evolutionary framework. Although evolutionary psychology has generated many interesting hypotheses, it faces a major challenge in developing methodologies to rigorously test these hypotheses [10]. Neither of the most powerful methods available to those studying non-humans, comparisons of different species or direct measurement of selective advantage under natural conditions, are available to those studying humans. The results of the two studies discussed here complement research with human subjects and offer strong support for the hypothesis that social settings provided an important context for the evolution of human intelligence [11 and 12]. Thus, important tests of hypotheses about the evolution of cognition in humans can be carried out with non-human subjects.
Many of the hypotheses that attempt to account for the evolution of human cognitive abilities are quite general, and need not be viewed as limited to primates, or even to mammals. The social complexity hypothesis holds that a highly structured social setting in which individuals are treated differentially (e.g. according to kin relationships and dominance status) provides a context for the evolution of cognitive abilities. There are, for example, many avian species that would provide tests of this hypothesis [13]. A recent study compared the performance of the highly social pinyon jay (Gymnorhinus cyanocephalus) with a much less social close relative, the western scrub jay (Aphelocoma californica) on an operant test of transitive inference [14]. The results showed la arge species difference, as predicted by the social complexity hypothesis.

\section{Mental continuity?}

The biological world presents a complex pattern that includes both continuity and discontinuity among taxa. As a result of common descent, continuity is evident at many levels, from the structure of DNA to behavior. But populations or species are separated by discontinuity as a result, ultimately, of reproductive isolation. But why, if the factors that favor the evolution of intelligence have produced the cognitive abilities of humans and non-humans alike, is there such a large apparent gap between humans and other animals in intelligence?

Part of the answer must be that the gap is smaller than it currently appears. A gap certainly exists, but we know too little about the cognitive world of non-humans, including primates, to have any confidence in just how large this gap is. The situation is analogous to 'gaps' in the fossil record. These gaps in the historical record of life are at least partly due to lack of evidence. As new fossils are found, they are much more likely to make these gaps decrease than increase in size. Similarly, new discoveries about the cognitive abilities of animals are likely to continue to reduce the size of the apparent discontinuity between human and non-human intelligence. The magnitude of the intellectual discontinuity between humans and other animals remains undetermined.

\section{Future directions}

These two papers demonstrate the potential value of long-term field studies to evaluate the knowledge animals possess about their social (and non-social) environments, and should encourage other field workers to investigate cognition in natural conditions [9]. From an evolutionary point of view, it would be particularly valuable to demonstrate a direct connection between knowledge and biological success. From a more mechanistic, cognitive perspective, the results of field studies can be very revealing about the knowledge animals possess and use under natural conditions. Even so, such field studies cannot determine how this knowledge is acquired. Laboratory work based on the results of field studies such as those reviewed here can play a crucial role in expanding our understanding of cognition in animals, human and non-human alike. 


\section{Acknowledgements}

I thank Guillermo Paz-Y-Miño C. and Debbie Kelly for their helpful comments. Preparation of this commentary supported by a grant from NIMH.

\section{References}

I. T.J. Bergman et al., Hierarchical classification by rank and kinship in baboons. Science 302 (2003), pp. I234-I 236.

2. J.B. Silk et al., Social bonds of female baboons enhance infant survival. Science 302 (2003), pp. I23 I-1234.

3. V. Dasser, A social concept in Java monkeys. Anim. Behav. 36 ( 1988$)$, pp. 225-230.

4. D.L. Cheney and R.M. Seyfarth. How Monkeys See the World, University of Chicago Press (1990).

5. D.L. Cheney and R.M. Seyfarth, Recognition of other individuals' social relationships by female baboons. Anim. Behav. 58 (1999), pp. 67-75.

6. J.B. Silk et al., The structure of social relationships among female savanna baboons in Moremi Reserve, Botswana. Behaviour I 36 (1999), pp. 679-703.
7. S. Pinker. The Language Instinct, Harper (1995).

8. D. Attwell and S.B. Laughlin, An energy budget for signaling in the grey matter of the brain. J. Cereb. Blood Flow Metab. 21 (200I), pp. I |33-I I 45.

9. R. Balda, I. Pepperberg and A.C. Kamil. Animal Cognition in Nature, Academic Press (1998).

I0. F.B.M. de Waal, Evolutionary psychology: the wheat and the chaff. Curr. Dir. Psychol. Sci. I I (2002), pp. I87-19I.

I I. R.W. Byrne and A.Whiten. Machiavellian Intelligence: Social Expertise and the Evolution of Intellect in Monkeys, Apes and Humans, Oxford University Press (1988).

I2. H. Kummer et al., The social intelligence hypothesis. In: P.Weingart et al.Human by Nature: Between Biology and the Social Sciences, Erlbaum (1997), pp. I57-179.

I3. R.P. Balda et al., Predicting cognitive capacities from natural histories: examples from four species of corvid. In: E. Ketterson and V. Nolan, Editors, Current Ornithology Vol. I3, Plenum Press (1996).

I4. A.B. Bond et al., Social complexity and transitive inference in corvids. Anim. Behav. 65 (2003), pp. 479-487. 